\title{
Dimensional Stability, Thermal Degradation and Termite Resistant Studies of Chemically Treated Wood
}

\author{
Juthika Sonowal (Corresponding author) \\ Department of Chemistry, Dibrugarh University \\ Dibrugarh- 786004, Assam, India
}

Tel: 91-995-443-5710Ｅ-mail: swjuthika@yahoo.co.in

\author{
P.K. Gogoi \\ Department of Chemistry, Dibrugarh University \\ Dibrugarh- 786004, Assam, India \\ Tel: 91-943-513-1158 E-mail: dr_pradip@yahoo.com
}

\begin{abstract}
The efficacy of the preservative chemicals for the treatment of wood samples was evaluated in ground contact against termite and fungus. The wood samples treated with boric acid followed by maleic anhydride, copper acetate, sodium salt of diethyldithiocarbamate and kerosene showed higher dimensional stability efficiency in terms of anti-shrink efficiency (ASE), bulk co-efficient (BC) and weight percent gain (WPG). The treated wood samples showed higher strength properties such as modulus of rupture (MOR) and modulus of elasticity (MOE) than the untreated sample. The treated samples could resist from termite and fungal attack and also extend the service life.
\end{abstract}

Keywords: Dimensional stability, Anti-shrink efficiency, Modulus of rupture, Modulus of elasticity, Termite resistance

\section{Introduction}

Wood is one of the most important renewable bioresources used by mankind since prehistoric days. It was used for making weapons, in constructing shelters and as fuel. Compared to other lignocellulosic materials, it has better mechanical strength and materials made of wood are of better aesthetic look. Even in this age of novel composite materials, wood is still a prized material in making furniture and used extensively in building construction. Wood contains mainly cellulose, hemicelluloses and lignin, the amount varies from species to species. However, like other lignocellulosic materials, wood is prone to degradation and dimensional variation on exposure to moisture, heat and biological agents like fungi, termite and wood boring insects which make it unfit for further use. In tropical and temperate region, termite pose the serious threat to untreated timber and other lignocellulosic materials used in various constructions. To protect wood from degradation and enhance its working life, various methods have been employed (Connell, M., 1991) during last hundred years, e.g. treating with mineral oil, coal tar, heating in hydrocarbon oil and treatment with CCA (copper-chrom-arsenic). Use of newly developed organochlorins, which are quite cheap and easy to produce, like aldrin, dieldrin, chlordane and sodium pentachlorophenoxide (Logan, J.W.M. \& Buckley, D.S., 1991) can control termite upto 30 years. Rowell reported (Rowell, R. M., 1991) various methods of treatment of wood to protect it from dimensional change and attack by insects. Because of their undesirable side effects and long persistence in soil, of late many of these organochlorine formulations have been removed from market. However, if some new formulations are devised, which may be cost effective, easy to prepare and apply, having low mobility in soil and relatively harmless in low concentration and adequately fixed in wood followed by sealing with hydrophobic agents to prevent leaching in contact with ground, it would be an ideal inhibitor. Further, to make it having a wide spectrum of activity some other chemicals in optimum concentration may be used in certain sequence.

Termite, fungi and other insects can degrade lignocellulosic materials as they contain the enzyme cellulase, which can decompose cellulose to glucose, a source of biochemical energy. If wood can be made resistant to degradation by heat and moisture and application of some active principle to inhibit the activity of cellulase enzyme, wood can be protected with enhanced working life. In this paper, we report the effect of treatment of wood with less toxic chemicals, in low concentrations, like boric acid, maleic anhydride, copper acetate, sodium 
salt of diethyldithiocarbamate and kerosene in arresting dimensional change and biodegradation. We also report a protocol for optimum use of chemicals in a particular sequence to get better results.

\section{Experimental}

\subsection{Raw material}

The second class wood samples for the experiments were collected from the wood mart at Dibrugarh, Assam. The wood samples were prepared for the treatment approximately of size $10.5 \times 3.0 \times 1.5 \mathrm{~cm}$ (length $\mathrm{x}$ breadth $\mathrm{x}$ thickness ).

The chemicals used for the treatment were:

(a) Boric acid (BA, Rankem, 5\% w/v in water)

(b) Copper acetate (CA, Rankem, $5 \% \mathrm{w} / \mathrm{v}$ in water)

(c) Maleic anhydride (MA, Merk, 5\% w/v in 1:1 DMF and MeOH)

(d) Diethyldithiocarbamate, Na-salt (DEDTC, BDH, $5 \% \mathrm{w} / \mathrm{v}$ in water)

(e) Kerosene (250ml)

\subsection{Chemical treatment}

For chemical treatment the samples were extracted separately with water followed by methanol and dichloromethane for $3 \mathrm{hrs}$ and then oven dried at $100 \pm 5^{\circ} \mathrm{C}$ so that at least $20 \%$ moisture remains inside the sample. Unlike other materials, wood is hygroscopic and exchange moisture with the surroundings as water can remain in the cell capillary and cell walls (Beauford, W., 1991). Microbial degradation can occur if moisture is more than $20 \%$ of the dry weight. The remaining $20 \%$ moisture is essential for diffusion of water soluble inhibitor. The chemical treatment of the wood samples were carried out as follows:

(a) For maleic anhydride treatment, the wood samples were dipped in maleic anhydride solution (in 1:1 DMF and $\mathrm{MeOH}$ ) for seven days and then air-dried followed by oven drying at $100 \pm 5^{\circ} \mathrm{C}$ for two hours.

(b) Other wood samples were first treated with the solution of boric acid for seven days and then air-dried followed by oven drying at $100 \pm 5^{\circ} \mathrm{C}$ for two hours and then again treated with copper acetate solution for seven days and then oven dried. After the treatment of boric acid and copper acetate, the samples were again treated with sodium salt of diethyldithiocarbamate solution for seven days.

(c) Another sample was treated with boric acid followed by maleic anhydride, copper acetate and sodium salt of diethyldithiocarbamate in a manner as described in (b) above.

After the completion of chemical treatment, all the samples were treated with kerosene for one day and air-dried.

\subsection{Evaluation of properties of treated and untreated samples}

The dimensional parameters such as volumetric swelling, anti-shrink efficiency (ASE), bulk co-efficient (BC) were calculated by reported method (Schneider, M.H. \& Brebner, K.I. 1985).

The weight percent gain (WPG) were determined by using the following relation:

$$
\mathrm{WPG}=\left(\mathrm{W}_{\mathrm{t}}-\mathrm{W}_{\mathrm{u}}\right) \times 100 / \mathrm{W}_{\mathrm{u}}
$$

Where, $\mathrm{W}_{\mathrm{t}}$ and $\mathrm{W}_{\mathrm{u}}$ were the oven dried weight of treated and untreated samples in gram.

The volumetric swelling coefficient (S) and anti shrink efficiency (ASE) were calculated by the following relations:

$$
\mathrm{S}_{\mathrm{u}, \mathrm{t}}=\left(\mathrm{V}_{\mathrm{w}}-\mathrm{V}_{\mathrm{u}, \mathrm{t}}\right) \times 100 / \mathrm{V}_{\mathrm{u}, \mathrm{t}}
$$

Where,

$\mathrm{V}_{\mathrm{w}}=$ swollen volume of wood sample after treatment in $\mathrm{cm}^{3}$

$\mathrm{V}_{\mathrm{u}, \mathrm{t}}=$ oven-dried volume of either treated and untreated samples in $\mathrm{cm}^{3}$

$$
\operatorname{ASE}=\left(S_{u}-S_{t}\right) \times 100 / S_{u}
$$

Where $S_{u}$ and $S_{t}$ were the volumetric swelling co-efficiency based on the oven dried volume of the untreated and treated sample in percentage.

Bulk- coefficient $(\mathrm{BC})$ were determined from the following relation:

$$
\mathrm{BC}=\left(\mathrm{V}_{\mathrm{t}}-\mathrm{V}_{\mathrm{u}}\right) \times 100 / \mathrm{V}_{\mathrm{u}}
$$


Where $\mathrm{V}_{\mathrm{t}}$ and $\mathrm{V}_{\mathrm{u}}$ were oven-dried volume of treated and untreated samples in $\mathrm{cm}^{3}$

Modulus of rupture (MOR) and modulus of elasticity (MOE) were determined according to IS: 2380 (1977).

$$
\mathrm{MOR}=3 \mathrm{PL} / 2 \mathrm{bd}^{2}
$$

Where $\mathrm{P}$ is the maximum load in $\mathrm{kg}, \mathrm{L}$ is the length of span in $\mathrm{cm}, \mathrm{b}$ is the width of the specimen in $\mathrm{cm}$ and $\mathrm{d}$ is the depth of the specimen in $\mathrm{cm}$.

$$
\mathrm{MOE}=\mathrm{P}_{1} \mathrm{~L}^{3} / 4 b d^{3} \mathrm{Y}
$$

Where $\mathrm{P}_{1}$ is the load in $\mathrm{kg}$ at the proportionality limit, $\mathrm{Y}$ is the central deflection at limit of proportionality load in $\mathrm{cm}$.

\section{Cellulase inhibition test}

In each of five $250 \mathrm{ml}$ beakers (marked 1 to 5 ), $60 \mathrm{ml}$ of phosphate buffer $\left(\mathrm{p}^{\mathrm{H}} 6.47\right)$ were taken, to each of which $1 \mathrm{~g}$. of wood powder(WP) were added. $5 \%(\mathrm{w} / \mathrm{v})$ of each of boric acid(BA), copper acetate $(\mathrm{CA})$, sodium salt of diethyldithiocarbamate(DEDTC) and a mixture of $5 \%(\mathrm{w} / \mathrm{v})$ each of BA,CA and DEDTC were added in the beaker no.2, 3, 4 and 5 respectively (table 2). To each beaker $6 \mathrm{ml}$ (300 units) of cellulase enzyme(Aldrich) were added. After adding chemicals and cellulase enzyme, the beakers were covered for 24 hours at room temperature, after which they were heated at $60^{\circ} \mathrm{C}$ for $1 \mathrm{hr}$ in water bath to stop the cellulase activity. After cooling to room temperature, the solutions were filtered and made up the volume to $100 \mathrm{ml}$ and glucose was estimated by Fehling solution using methylene blue indicator relative to a standard glucose solution.

\section{Thermal studies}

Simultaneous thermogravimetry and differential thermal analysis of treated and untreated wood samples were carried out using Perkin Elmer Pyris Dimond TG/DTA instrument at a heating rate of $20^{\circ} \mathrm{C} / \mathrm{min}$ and the temperature range from $40-500^{\circ} \mathrm{C}$ in static atmosphere. The weight of the samples were taken in the range of 5.0 $-10.34 \mathrm{mg}$ and $\alpha$-alumina was used as a reference material.

\section{SEM studies}

To study the penetration of chemicals into wood structure, the SEMs of treated and untreated samples were recorded at Indian Institute of Technology, Guwahati, on a LEO 1430VP Scanning Electron Microscope.

\section{Graveyard test}

The evaluation of termite resistance capacity was carried out as per reported method (Kumar et.al. 1998). The treated and untreated samples were buried in ground under normal condition. After one year burial test, they were exhumed and examined visually.

\section{Results and discussion}

Table 1 shows the dimensional variations of wood samples treated with different chemicals and their combinations in terms of antishrink efficiency(ASE) along with bulk coefficient(BC) and weight percent gain(WPG). The sample treated with only maleic anhydride gave good bulk coefficient and weight percent gain because of reaction of the dicarboxylic acid anhydride and $\mathrm{OH}$ group of the cellulose to give esterified wood with carbonyl group resulting enhanced dimensional stability as follows (Matsuda, H., 1996)

$$
\text { Wood-OH }+ \text { maleic anhydride } \rightarrow \text { Wood-OOC-R-COOH }
$$

However, the maximum ASE (58.14\%) at the level of $27.82 \%$ WPG was shown by the sample treated with boric acid followed by maleic anhydride, copper acetate, sodium salt of DEDTC and kerosene. The sample so treated also showed total protection from termite compared to only maleic anhydride and kerosene treated sample. Similarly the sample treated with boric acid, copper acetate and DEDTC showed good biodegradation inhibition but the dimensional stability was not optimum. Lignocellulosic materials are degraded by termites and fungus which contain cellulase enzyme. In the mechanism (White, A.R., 1982) of the cellulase action, it is found that the Tricoderma cellulase consists of three enzyme systems, (a) endoglucanase (EG), (b) cellubiohydrolase (CBH) and (c) $\beta$-glucosidase ( $\beta$-G). EG first attact the cellulose fiber and breaks the glucosyl bond of the glucan chain and expose the reducing and non-reducing end. $\mathrm{CBH}$ then attact the free non-reducing chain end and cellobiose is released where it is converted to glucose by $\beta-G$ and the synergistic degradation of cellulose is completed. The inhibition of cellulase activity and dimensional stabilization may be concurrently considered from two angles: (i) application of cellulase activity inhibitor and (ii) chemical modification of the - $\mathrm{OH}$ group of the non-reducing chain end, the site of $\mathrm{CBH}$ attack; the - $\mathrm{OH}$ groups are not only enzyme attack sites but also water absorption sites through hydrogen bonding, which facilitate swelling. In the cellulase activity experiment (table 2) it was observed that in presence of boric acid and copper acetate the cellulase activity is slightly reduced. It was 
reported earlier that (Vyas et.al., 2005) in alkaline media cellulase activity is enhanced compared to acidic media. Hence presence of boric acid and copper acetate - which may hydrolyse to give slightly acidic medium due to presence of acetic acid, inhibit the cellulase activity. But in presence of boric acid and copper dithiocarbamate, there is substantial decrease of cellulase activity as seen from the amount of glucose released.

From the thermal analysis data (table 3), it was seen that compared to untreated sample, there is substantial decrease in both major decomposition temperature range and percent weight loss for the treated samples. The active decomposition temperature was highest for maleic anhydride treated sample indicating increased bulking and $\mathrm{OH}$ group modification to give good dimensional stability. In other treated samples the active decomposition temperature is similar to untreated one, which could be due to easy decomposition of DEDTC during respective major decomposition temperature ranges. Although only maleic anhydride treated sample gave good dimensional stability in terms of ASE, BC, MOR and MOE (table 4) it failed to give total termite protection.

From the measurement of strength (MOR) and stiffness (MOE) of both untreated and treated samples, it was observed that there is increase in the modulus of rupture and modulus of elasticity of the treated samples. It could be due to chemical modification of cellulose by maleic anhydride and physical bulking by copper acetate, boric acid and DEDTC. There is good correlation of dimensional characteristics, cellulase inhibition activity, thermal property and mechanical properties of chemically treated wood.

Scanning electron micrographs showed the penetration of chemicals inside the wood that resulted in bulking of the cell wall to give dimensionally stabilized wood. Changes in internal structure of the cell wall due to the presence of chemicals were observed by SEM studies. The white patches which were seen in the micrograph were the chemicals observed on the cell walls of the wood (Fig.6)

After the one year of graveyard test, it was observed that(Fig.7) compared to untreated sample the sample treated only with MA was slightly damaged by termite followed by BA, CA and DEDTC and the sample treated with BA,MA,CA and DEDTC was not at all damaged. Boric acid, copper salts and ditihiocarbamate all have antibacterial and antifungal activity. Because of antifungal, bacteriocidal and insecticidal activity, dimethyl dithiocarbamate of copper has been patented (Batterrshell et al, 1998) in U.S. as wood preservative. Boric acid has been reported as stomach poison for insects (Yamaguchi, H., 2003). Similarly, transition metal compounds of dithiocarbamates and dithiophosphinates are known antifungal and antibacterial agents (Kalita, et.al. 2002) and the mode of action being inhibition of certain vital enzymes by the sulphur donors, the $\mathrm{Cu}^{2+}$ also can inhibit action of several biomolecules. Dithiocompounds also inhibit the enzyme actylcholinesterase (Gruzdyev et al, 1980). As these chemicals are easily leached in contact with water, kerosene is used to create hydrophobic environment inside and on the surface of the samples to prevent leaching of preservatives and stop penetration of moisture, which also help to retain dimensional stability. Further, petroleum oils like kerosene have low toxicity to warm blooded animals but prevents metabolism in egg or insect body. The oil can easily penetrate through the wax scale and cuticles, can cause coagulation of the cytoplasma and inhibit the course of enzyme process (Gruzdyev et.al., 1980). Compared to other chemical methods of treatment of wood, the present method appears to be better in the sense that the chemicals are cost effective, can be handled and applied easily and less toxic at low concentration but at the same time give very good results.

\section{Conclusion}

Dimensional stability and resistance of biodegradation by chemical treatment of lignocellulosic materials depends upon the type of chemicals and their penetration and how much hydroxyl groups are modified to give adequate cross-linking and bulkiness. From the present studies, it may be concluded that wood samples treated with boric acid followed by maleic anhydride, copper acetate, diethyldithiocarbamate and kerosene were more dimensional stability and can resist termite and fungal attack better where kerosene creates hydrophobic environment inside and surface of the samples.

\section{References}

Battershell, R. D., Jacobson, B. M., Abraham, A. C., Pereira, B. M. \& Kempf, J. V. (1998). United States Patent No.5731036. March 24.

Beauford, W. (1991). In-situ and suplimentary treatments using solid water diffusible preservatives. In R. Thompson (Ed.), The chemistry of wood preservation (pp.53-68). The Royal Society of Chemistry, Cambridge.

Bureau of Indian Standards. (1977). Method of test for wood particle boards and boards from lignocellulosic materials. Indian Standard Institution. IS : 2380. New Delhi. 
Connell, M. (1991). Industrial wood preservatives- The history, development, use, advantages and future trends. In R. Thompson (Ed.), The chemistry of wood preservation (pp.16-33).The Royal Society of Chemistry, Cambridge.

Gruzdyev, G.S., Zinchenko, V.A., Kalinin, V.A., \& Slovtsov, R.I. (1980). Means for controlling plant pests. In G. S. Gruzdyev (Ed), The chemical protection of plants, (pp. 236-239). Mir Publishers, Moscow.

Gruzdyev, G.S., Zinchenko, V.A., Kalinin, V.A., \& Slovtsov, R.I. (1980). Fungicides. In G. S. Gruzdyev (Ed), The chemical protection of plants (pp. 280-288). Mir Publishers, Moscow.

Kalita, D. K., Das, D. K. \& Gogoi P. K. (2002). Synthesis, characterization and antibacterial activity of 2methylpiperazine dithiocarbamates of $\mathrm{Ru}(\mathrm{III}), \mathrm{Rh}(\mathrm{III}), \mathrm{Pd}(\mathrm{II}), \mathrm{Os}((\mathrm{III})$ and $\mathrm{Pt}(\mathrm{II})$. Proceedings of National Academy of Sciences, India. 72(A), 7-13.

Kumar, S., Kainth, P. S. \& Chauhan, K. S. (1998). Natural durability and graveyard performance of preservative treated bamboos. Journal of Timber Development Association (India). 44(3), 17-24.

Logan, J. W. M. \& Buckley, D. S. (1991). Subterranean termite control in buildings. In R. Thompson (Ed.). The chemistry of wood preservation, (pp. 294-305). The Royal Society of Chemistry, Cambridge.

Matsuda, H. (1996). Chemical modification of solid wood. In David N. -S. (Ed.). Chemical modification of lignocellulosic material, (pp.169). Marcel Dekker, New York.

Rowell, R. M. (1991). Chemical modification of wood. In David N. -S. Hon \& N. Shiraishi (Eds). Wood and cellulosic chemistry (pp. 703- 756). Marcel Dekker, Inc., New York.

Schneider, M. H. \& Brebner, K. I. (1985). Wood and polymer combination: The chemical modification of wood by alkoxysilane coupling agents. Wood Science and Technology, 19, 67-73.

Vyas, A., Jain, A., Vyas, D. \& Vyas, K. M. (2005). Production and partial characterization of cellulases by two Aspergillus spp on pretreated low value lignocelluloses. Proceedings of National Academy of Sciences, India. 75(B), 1, 51-57.

White, A. R. (1982). Vizualization of cellulases and cellulose degradation. In R.D. Brown Jr. (Ed.), Cellulose and other natural polymer system: Biogenesis, structure and degradation (pp. 489-506). Plenum Press, New York.

Yamaguchi, H. (2003). Silicic acid: boric acid complexes as wood preservatives. Wood Science and Technology, $37,287-297$.

Table 1. Dimensional characteristics

\begin{tabular}{|l|l|l|l|}
\hline Chemicals used & ASE (\%) & BC (\%) & WPG (\%) \\
\hline MA, Kerosene & 52.95 & 5.14 & 23.77 \\
\hline BA, CA, DEDTC, Kerosene & 54.31 & 5.47 & 25.01 \\
\hline BA, MA, CA, DEDTC, Kerosene & 58.14 & 6.08 & 27.82 \\
\hline
\end{tabular}

Table 2. Cellulase activity data

\begin{tabular}{|l|l|c|}
\hline Sl.No. & Chemicals used & Amount of glucose $(\mathrm{gm} / 100 \mathrm{ml})$ \\
\hline 1 & WP+Cellulase & 0.358 \\
\hline 2 & WP+BA+ Cellulase & 0.297 \\
\hline 3 & WP+CA+ Cellulase & 0.296 \\
\hline 4 & WP+DEDTC+ Cellulase & 0.223 \\
\hline 5 & WP+BA+CA+DEDTC+ Cellulase & 0.190 \\
\hline
\end{tabular}


Table 3. Thermal analysis data

\begin{tabular}{|c|c|c|c|}
\hline Chemicals used & Major decomp. temperature & Wt. loss & Active decomp. temperature \\
\hline & $\left({ }^{0} \mathrm{C}\right)$ & $(\%)$ & $\left({ }^{\circ} \mathrm{C}\right)$ \\
\hline untreated & $241.85-489.25$ & 85.14 & 335.29 \\
\hline MA, Kerosene & $236.59-405.25$ & 63.04 & 351.66 \\
\hline BA, CA, DEDTC, Kerosene & $200.52-381.97$ & 61.78 & 337.67 \\
\hline BA, MA, CA, DEDTC, Kerosene & $209.74-393.08$ & 60.35 & 346.59 \\
\hline
\end{tabular}

Table 4. Effect of chemical treatment on strength (MOR) and stiffness (MOE) of wood

\begin{tabular}{|l|l|l|}
\hline Chemicals used & MOR $\left(\mathrm{N} / \mathrm{mm}^{2}\right)$ & $\mathrm{MOE}\left(\mathrm{N} / \mathrm{mm}^{2}\right)$ \\
\hline Untreated & 50.44 & 6616.26 \\
\hline MA, Kerosene & 61.06 & 7867.49 \\
\hline BA, CA, DEDTC, Kerosene & 62.20 & 8281.57 \\
\hline BA, MA, CA, DEDTC, Kerosene & 65.87 & 9510.87 \\
\hline
\end{tabular}

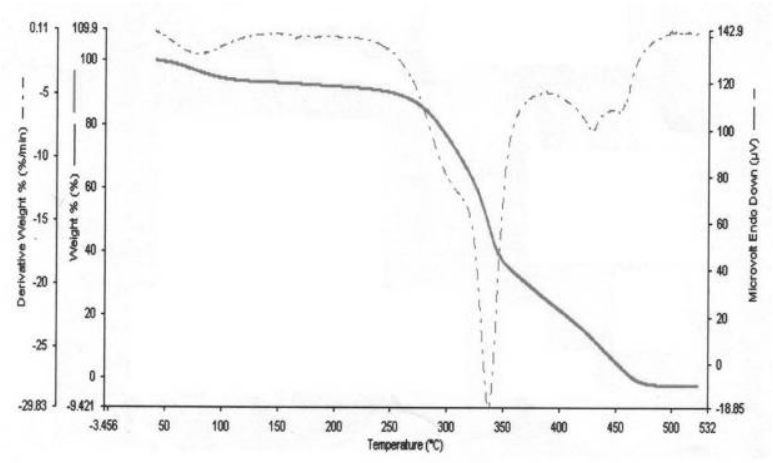

Figure 1. Thermogram of untreated wood sample

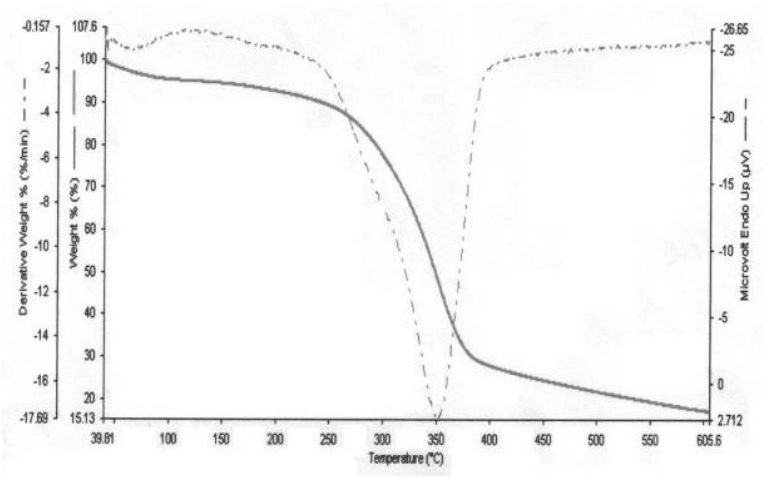

Figure 2. Thermogram of MA and kerosene treated wood sample 


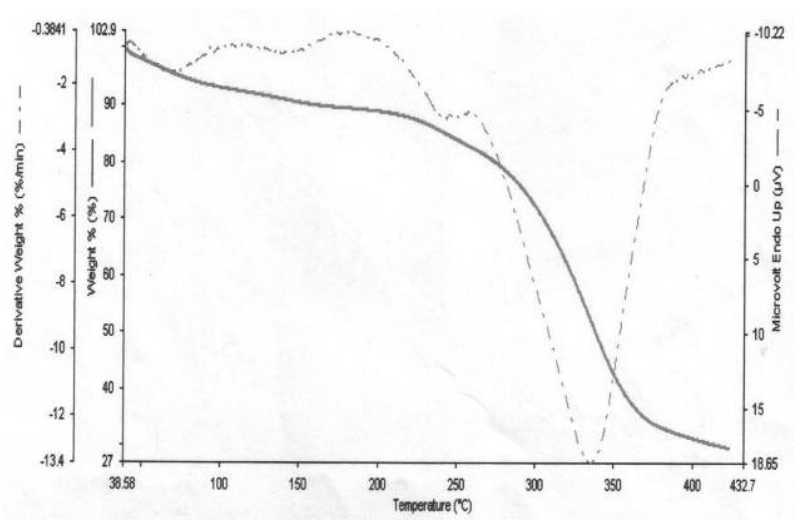

Figure 3. Thermogram of BA, CA, DEDTC and kerosene treated sample

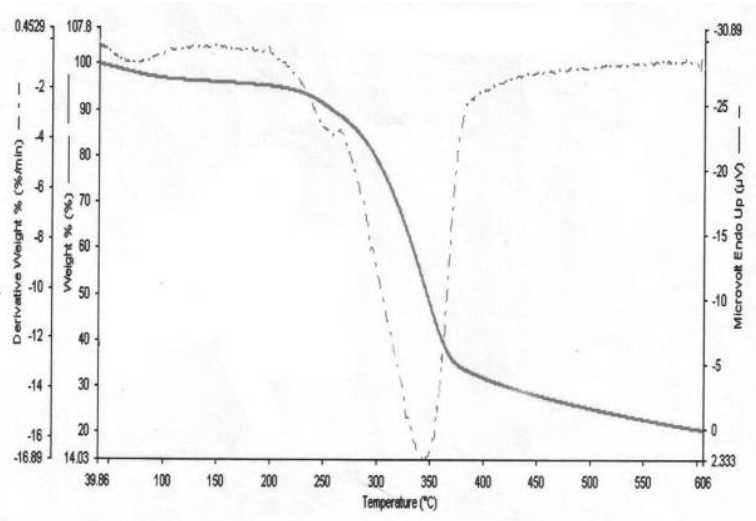

Figure 4. Thermogram of BA, MA, CA, DEDTC and kerosene treated wood sample

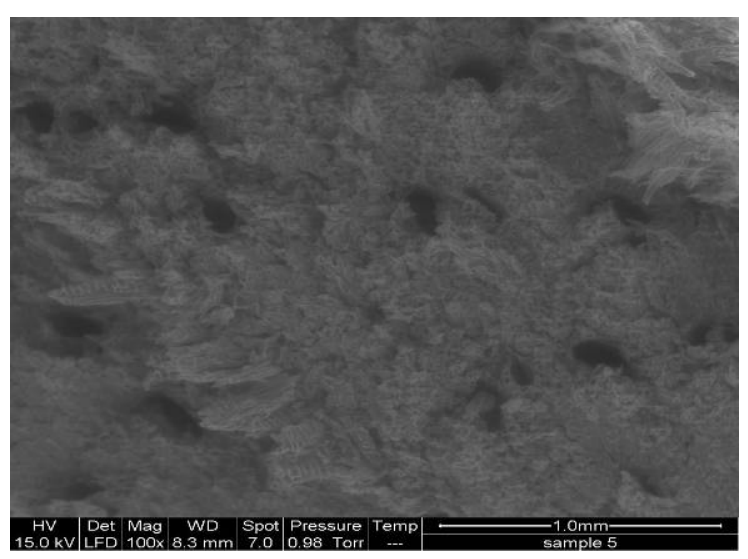

Figure 5. SEM pattern of untreated wood 


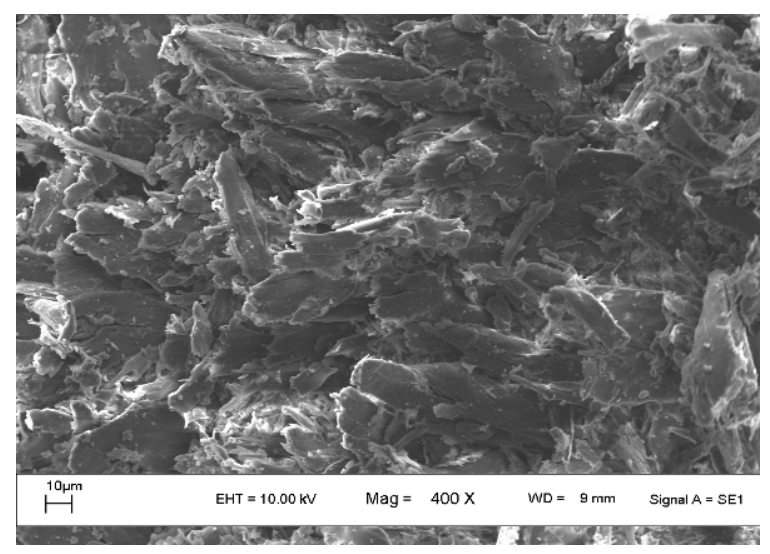

Figure 6. SEM pattern of BA, MA, CA, DEDTC and kerosene treated wood

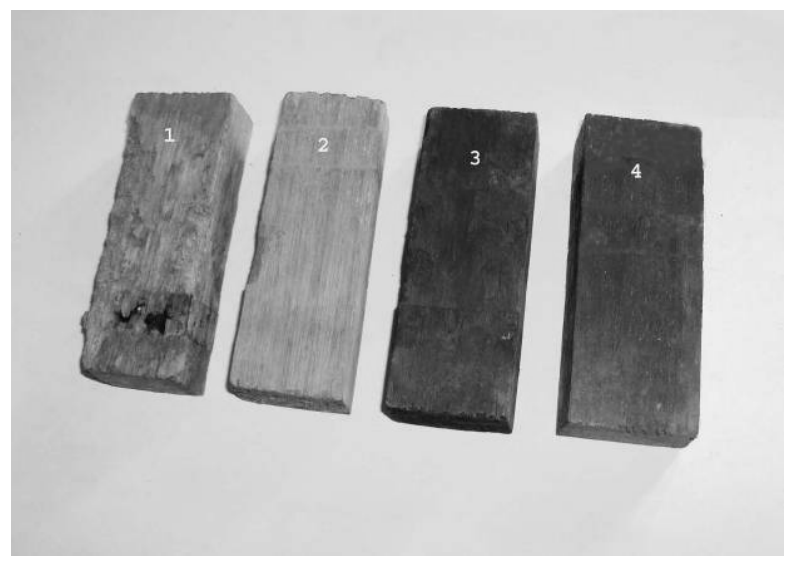

Figure 7. Wood samples after one year of graveyard test

1. Untreated

2. MA and Kerosene treated

3. BA, CA, DEDTC and Kerosene treated

4. BA, MA, BA, CA, DEDTC and Kerosene treated 